\title{
Erratum to: Highly efficient Agrobacterium-mediated transformation of banana cv. Rasthali (AAB) via sonication and vacuum infiltration
}

\author{
Kondeti Subramanyam • Koona Subramanyam • \\ K. V. Sailaja • M. Srinivasulu $\cdot$ K. Lakshmidevi
}

Published online: 21 January 2011

(C) Springer-Verlag 2011

\section{Erratum to: Plant Cell Rep}

DOI 10.1007/s00299-010-0996-4

In the original version of the article, some of the significance values were accidentally omitted in the fifth column of Table 3. The correct version of the table is given in the following page.

The online version of the original article can be found under doi:10.1007/s00299-010-0996-4.

Kondeti Subramanyam · K. V. Sailaja $\cdot$ K. Lakshmidevi $(\bowtie)$ Department of Biochemistry, Sri Krishnadevaraya University, Anantapur, Andhra Pradesh 515055, India

e-mail: prasamshika1@gmail.com

Koona Subramanyam

Department of Biotechnology, Sreenidhi Institute of Science and

Technology (Autonomous), Jawaharlal Nehru Technological

University, Hyderabad, Andhra Pradesh 501301, India

M. Srinivasulu

Department of Microbiology, Sri Krishnadevaraya University,

Anantapur, Andhra Pradesh 515055, India 
Table 3 Effect of sonication and vacuum infiltration on the number of GUS positive shoots after 3 days of co-cultivation with Agrobacterium strain EHA105 harboring pCAMBIA1301 plasmid in co-cultivation medium supplemented with $50 \mu \mathrm{M}$ acetosyringone

\begin{tabular}{|c|c|c|c|c|c|c|}
\hline $\begin{array}{l}\text { Sonication } \\
(\mathrm{min})\end{array}$ & $\begin{array}{l}\text { Vacuum } \\
\text { treatment (min) }\end{array}$ & $\begin{array}{l}\text { No. of suckers } \\
\text { infected }^{A}\end{array}$ & $\begin{array}{l}\text { No. of suckers } \\
\text { formed shoots }{ }^{\mathrm{B}}(\%)\end{array}$ & $\begin{array}{l}\text { Total no. of } \\
\text { shoots } \mathrm{C}\end{array}$ & $\begin{array}{l}\text { No. of GUS } \\
\text { positive shoots }\end{array}$ & $\begin{array}{l}\text { Percentage of GUS } \\
\text { positive shoots }\end{array}$ \\
\hline 0 & - & 10 & $8(80)$ & $136.0 \pm 0.5^{\mathrm{a}}$ & $39.1 \pm 0.4^{\mathrm{b}}$ & $28.6 \pm 0.5^{\mathrm{e}}$ \\
\hline 2 & - & 10 & $8(80)$ & $130.8 \pm 0.3^{\mathrm{b}}$ & $40.4 \pm 0.2^{\mathrm{a}}$ & $30.8 \pm 0.2^{\mathrm{cd}}$ \\
\hline 4 & - & 10 & $8(80)$ & $125.0 \pm 0.4^{\mathrm{c}}$ & $39.1 \pm 0.4^{\mathrm{b}}$ & $31.2 \pm 0.3^{\mathrm{c}}$ \\
\hline 6 & - & 10 & $7(70)$ & $91.8 \pm 0.5^{\mathrm{d}}$ & $32.1 \pm 0.4^{\mathrm{c}}$ & $34.9 \pm 0.5^{\mathrm{a}}$ \\
\hline 8 & - & 10 & 7 (70) & $88.1 \pm 0.2^{\mathrm{e}}$ & $29.3 \pm 0.5^{\mathrm{d}}$ & $33.3 \pm 0.5^{\mathrm{b}}$ \\
\hline 10 & - & 10 & $5(50)$ & $72.1 \pm 0.3^{\mathrm{f}}$ & $21.2 \pm 0.1^{\mathrm{e}}$ & $29.3 \pm 0.2^{\mathrm{d}}$ \\
\hline- & 0 & 10 & $8(80)$ & $135.9 \pm 0.2^{\mathrm{a}}$ & $39.0 \pm 0.3^{\mathrm{b}}$ & $28.6 \pm 0.2^{\mathrm{e}}$ \\
\hline- & 2 & 10 & $8(80)$ & $132.3 \pm 0.2^{\mathrm{b}}$ & $41.4 \pm 0.2^{\mathrm{a}}$ & $31.2 \pm 0.1^{\mathrm{cd}}$ \\
\hline- & 4 & 10 & $7(70)$ & $110.9 \pm 0.3^{\mathrm{c}}$ & $35.4 \pm 0.2^{\mathrm{c}}$ & $31.9 \pm 0.2^{\mathrm{c}}$ \\
\hline- & 6 & 10 & $7(70)$ & $95.1 \pm 0.3^{\mathrm{d}}$ & $34.1 \pm 0.2^{\mathrm{d}}$ & $35.8 \pm 0.3^{\mathrm{a}}$ \\
\hline- & 8 & 10 & $6(60)$ & $68.1 \pm 0.2^{\mathrm{e}}$ & $23.3 \pm 0.5^{\mathrm{e}}$ & $34.1 \pm 0.5^{b}$ \\
\hline- & 10 & 10 & $5(50)$ & $52.2 \pm 0.3^{\mathrm{f}}$ & $16.1 \pm 0.3^{\mathrm{f}}$ & $30.8 \pm 0.5^{\mathrm{d}}$ \\
\hline 2 & 2 & 10 & $7(70)$ & $113.4 \pm 0.5^{\mathrm{a}}$ & $36.1 \pm 0.5^{\mathrm{a}}$ & $31.8 \pm 0.5^{\mathrm{e}}$ \\
\hline 4 & 4 & 10 & $7(70)$ & $101.0 \pm 0.2^{\mathrm{b}}$ & $34.1 \pm 0.4^{\mathrm{b}}$ & $33.7 \pm 0.5^{\mathrm{c}}$ \\
\hline 6 & 6 & 10 & $5(50)$ & $61.1 \pm 0.4^{\mathrm{c}}$ & $24.1 \pm 0.4^{\mathrm{c}}$ & $39.4 \pm 0.5^{\mathrm{a}}$ \\
\hline 8 & 8 & 10 & $5(50)$ & $58.2 \pm 0.5^{\mathrm{d}}$ & $21.3 \pm 0.3^{\mathrm{d}}$ & $36.5 \pm 0.4^{\mathrm{b}}$ \\
\hline 10 & 10 & 10 & $3(30)$ & $28.3 \pm 0.5^{\mathrm{e}}$ & $9.2 \pm 0.4^{\mathrm{e}}$ & $32.6 \pm 0.2^{\mathrm{d}}$ \\
\hline
\end{tabular}

Mean values ( \pm standard errors) with different superscript letters (a, b, c, d, e and f) indicate significant different $(P<0.05)$

A Number of Agrobacterium infected banana suckers

B Number of suckers responded to shoot induction after Agrobacterium infection, \% (responded percentage), B/A $\times 100$

C Total number of shoots formed from the suckers after Agrobacterium infection

D Number of GUS positive shoots identified after GUS assay

E Percentage of Gus positive shoots: $\mathrm{D} / \mathrm{C} \times 100$. Mean values of three independent experiments \pm standard errors 